\title{
A Review:
}

\section{The Ancient Origins of Oral Pathology}

\author{
A. Wallace PARK ${ }^{1}$, DDSc, DDS, PhD, MSc, MDS, \\ CBiol, FIBiol, MRCPath and Hashim B. YAACOB ${ }^{2}$, BDS, \\ MSc, FDSRCPS, AM.
}

(Received 9 April and accepted 20 May 1991)

\begin{abstract}
Key words: oral pathology, paleopathology, paleontological origins, ancient diseases

Belief in a golden age has provided mankind with solace in times of despair and with elan during the expansive periods of history. Dreamers imagine the golden age in the remote past, in paradise lost, free from toil and grief. Optimists put their faith in the future and believe that mankind, Prometheus-like, will master the arts of life through power and knowledge. Thus, the golden age means different things to different men, but the very belief in its existence implies the conviction that perfect health and happiness are birthrights of men. Yet, in reality, complete freedom from disease and from struggle is almost incompatible with the process of living.
\end{abstract}

René Dubos 1959

\section{Disciplinary emergence and aims}

The foundation of medical pathological anatomy is attributed to Rudolf Virchow (1821-1902), who first related clinical disease to cellular pathology. In addition, Virchow played a major role in the development of public health laws in Germany, which may well have stemmed from his recognition that most diseases occur through interaction of an exogenous etiological agent with a susceptible host. The underlying concept of Virchow's health laws appears to have been the role of medicine, which he considered responsible for the constitution of society on a physiological basis.

In its modern context, oral pathology is an important younger extension of general pathology in relation to the scientific study of the etiology and effects of oro-facial disease. Oral diseases are either restricted to the mouth and facial region, or are systemic in origin and involve the oro-facial region as a partial manifestation, and may possibly influence localized diseases already present.

The roles of medicine and dentistry share a common aim, which is basically a restatement of Virchow's ideas:

1. The promotion of health

2. The prevention of illness

3. The restoration of health

4. Rehabilitation

In a simplistic sense, disease can arise from two main sources-biotic and non-biotic. Biotic diseases include derangements of structure, function and chemistry relative to the living system, and intruders such as viruses, bacteria, fungi and parasites. Non-biotic diseases include chemical and physical agents either alien to the living system or in amounts far in excess of tissue control.

1 Visiting Professor at the Faculty of Dentistry, University of Malaya, Kuala Lumpur, Malaysia.

2 Professor of Oral Pathology, Faculty of Dentistry, University of Malaya, Kuala Lumpur, Malaysia.

To whom all correspondence should be addressed: Dr. A. Wallace Park, 8 Cross View, Norham, Berwick-upon-Tweed, TD15 2LH, England, UNITED KINGDOM. 
The pattern of disease in both humans and animals is an expression of the life stresses to which they are exposed-in other words, a response to everything in their environment and behavior. Hence the way a disease is manifested is a reflection of genetic inheritance (a type of internal environment), the climate and the land on which they live, and other fauna and flora which co-exist with them. Further, it is influenced by occupation, dietary habit, housing type, clothing, and social structure including religious beliefs and mythology.

Pathological studies, irrespective of whether they fall within the area of general or oral pathology, can be viewed as a comparative examination of the occurrence and distribution of diseases of peoples and animals belonging to different communities across the globe and a correlation of the findings with social and geographical environment. This field is obviously much wider than a regional distribution, since it includes investigation of various ethnic, national, social and occupational groups in different regions as well as in a single area, and epidemiology and demography are also an integral part of it.

Examination of human remains is one of the pioneer disciplines of human biology, and comparative work on the skeleton goes back to the 16th century. In spite of this early start, however, accurate work did not appear until after 1800 . Some initial attempts in the study of fossil bones are of interest, and in this context Felix Platter (16th century) described what he regarded as bones of an early giant human race, but which later turned out to be those of a fossil elephant ${ }^{[1]}$. Such misinterpretation was not unusual, because a Zürich naturalist in the 18 th century described bones of a giant salamander which he claimed were those of a man drowned in the Biblical flood!

With the emergence of pathological anatomy in the middle of the 19th century, interest in the subject grew, and the new pathologists were joined by anthropologists and paleontologists, thus launching a new discipline known as paleopathology. This is the science of diseases which can be demonstrated in human and animal remains of ancient lineage, and in particular times for which no literary sources exist. The underlying aim of the new discipline is to assess for both individuals as well as groups the full significance of diseases, while bearing in mind that the link between culture and disease can be a two-edged sword by which the health status of a population can greatly influence its cultural advance or indeed its survival.

Current thinking accepts that paleopathology has a major role in the study of human and animal biology, since:

1. It can supply material evidence for both prehistoric and historic variations in the disease spectrum-in short, a temporal dimension to the geography of disease.

2. In the case of congenital anomalies with a known genetic link, information on aspects of heritable variation may be obtained, with a spectrum ranging from single gene differences to chromosomal aberrations.

3. Finally, it can provide a certain amount of information which can be incorporated into a paleodemographic framework. 


\section{Human pathological sources in antiquity}

Acquisition of information on ancient diseases relies on two main sources: some part or remnant of a former living body, and documents and artifacts, including carvings, paintings, castings, embroidered fabrics, coins and surgical instruments.

With regard to body remnants, the information which can be derived depends on the state of preservation of the particular tissue. If we take a good example, the club-foot of Pharaoh Siptah (Fig. 1), XIX Dynasty (1215. B.C.) provides a high-class piece of anatomical evidence against which there can be little argument ${ }^{[1,2]}$. At the other end of the spectrum there may be bone fragments badly eroded by acid soils or even crusted with deposits, which yield very little information and leave several avenues of uncertainty with regard to disease diagnosis.

Obviously, the most resistant body tissues are those with a high degree of mineralization, and therefore both bones and teeth tend to survive best. Bones provide better disease pointers, but under certain conditions such as those at the Niah caves in Sarawak, fossilization is not possible, whereas in parts of Europe percolation and infusion of minerals ensures protection. The range of preservation of body remains is considerable among environments such as volcanic tufas, peat bogs, lacustrine sediments and the caves of Chou Kou Tien ${ }^{[3]}$. If we take some of the more common earth types in which bones may be buried, it is of interest to note that chalk soil, being permeable, yields bones that are both corroded and weak. Earth in caves can be from a wide range of sources, and includes clays, loams, sands and gravels due to water action, or consolidated dusts. In addition, there are soils combined with limestone cemented together with calcium carbonate or loose fragments covered by precipitated carbonate. Gravel beds can have varying effects on bone, since the preservation depends on the acidity and permeability, and whether the deposit is anaerobic and waterlogged. Sand is a common bed for bones, but varies considerably in acidity. Sand conditions such as those in Egypt and South America have been found to preserve tissues such as skin and hair. Clay can lead to acid corrosion of bones, but with certain types of subsoil, preservation is possible. Bones have been recovered from saline soils, but are difficult to handle and are often damaged.

Second to bone for disease orientation are mummified bodies, of which there are two types, first the deliberately preserved bodies of Egypt and Peru, and second those resulting from desiccation in hot sandy deserts.

In the contrived mummy, the methods of embalming differed throughout the Egyptian dynasties, but the main ingredients used were sodium carbonate, resin and spices. The custom of mummifying is undertaken elsewhere in the world and practiced in various forms such as in Sulawesi where the body is placed in tree branches; smoke-drying is used by the Naga of Assam, while in North America, mummies have been found from Alaska to Mexico. In South America, Peruvian mummies are found in large numbers and in varying states of preservation. Surprisingly, however, the bodies found in certain peat bogs of Denmark and Germany (Tollund man and Wideby girl from Schleswig) are in a better state of 
preservation than the best of Egyptian mummies.

In addition to bones and mummification, there are two further sources, preservation by freezing as found in the Altai region of Central Asia, the Arctic and the Andes, and finally cremated remains, which often yield evidence of caries, arthritis and fractures.

A major source of disease evidence involves records of various forms. There are numerous writings of historians, philosophers, priests and medical writers, all of whom can throw light on the diseases and problems of their time. Examples of such writings include the papyri from the Middle and New Kingdoms of dynastic Egypt, such as the Ramesseum and Kahûn papyri (2080-1640 B. C.) and the Ebers (1550 B.C.), Hearst (1550 B.C.), Erman (1550 B.C.), Edwin Smith (1700 B. C.), London Medical (1350 B.C.) and Berlin Medical (1570-1075 B.C.) papyri ${ }^{[2,4]}$. Numerous texts have been recovered from Mesopotamia (Babylonia and Assyria), and around 1750 B. C., Hammurabi, king of Babylonia, compiled his famous Code of Laws in which reference is made to diseases. Material of medical interest also appears in the Bible, the Apocrypha, the Pseudepigrapha and the Talmud. The Talmud consists of two separate texts, the Babylonian (400 A.D.) and the Israeli $(500 \text { A.D. })^{[4]}$. From India, one written source of medical information emerged from the religious hymns of the Hindus known as the Vedas, the oldest of which is probably the Rig-Veda (2000-1500 B. C.) followed by the Athawa-Veda (1200 B. C.) and the later Yajur-Vedas. Further sources are the Sushruta and Charaka Samhitas $(600-400 \text { B. C. })^{[5,6]}$. The 5th century B. C. is represented by the casebooks of Hippocrates in Greece ${ }^{[1]}$ and their Roman counterpart, the "De Medicina" by Celsus (14-37 A.D.). Information from China stems from oracle-bone writings on scapulae and tortoise shells (1500-1000 B.C.), epigraphical evidence from seals in tombs of the first millennium B.C., more extensive texts from Shu Ching and the Shih Ching around 900 B.C., the outstanding classic Huang Ti Nei Ching (The Yellow Emperor's Manual of Corporeal (Medicine]) corpus based on a series of tractates written about 100 B.C. in the Former Han dynasty, and the first dynastic history, the Shih Chi, written around 90 B.C. Other ancient texts dealing specifically with dental problems in their narrowest context are incorporated within the papyri of Ebers and Hearst ${ }^{[4,7]}$.

Art forms can provide considerable insight into body shape and size relative to disease processes. Practically all forms of artistic representation using many different materials have been recovered, but only a few provide information of a definitive disease. Paintings located in tombs, temples and caves have depicted ancient man with some of the more obvious disease features, such as dwarfism, hunched backs due possibly to tuberculosis, or the protruding ribs of starvation or disease. Speculation about possible diseases can be endless, and the problem of interpreting the ineptitude of the artist or stylistic convention remain major obstacles. In addition to paintings there are numerous statues, statuettes and figurines made of metal, stone, clay or wood; there are bas-relief illustrations, masks, medallions, amulets, lamps and numerous forms of vessels and pottery. A few fabrics and painted leather fragments have been found intact.

Vessels used in ancient Peruvian cultures add another dimension to the 
disease archive, including a masked pottery vase depicting thyrotoxicosis and a jug suggesting morbid obesity-both from the Mochica period. Egyptian dynastic drawings depict club foot, an amulet from Nippur (1000 B. C.) shows the parasite Ascaris lumbricoides, while parts of the Bayeux Tapestry show abnormal body forms and growth. Coins can give hints of disease problems; Vespasian appears to have been markedly edentulous, while Maximianus Herculius (284-308 A.D.) seems to have had a broken nose ${ }^{[2]}$.

A further interesting source of information is physician's or surgeon's tools, backed by written accounts of treated cases. Very little of significance has emerged with regard to tools, yet the Egyptians, for example, must have used a whole group of instruments but without the discovery of a "surgeon's tray", one knife or retractor looks like another and there is no evidence of any specific role. The Egyptian temple of Kom Omboi displays a set of instruments on a relief-very similar to surgical instruments but they may well be the tools of a goldsmith. Readings from the Ebers Papyrus include comments about wounds, fractures and dislocations but hardly any operative surgery. This is not, perhaps, so surprising since the subject was regarded as a craft to be learned by experience. The only instrument mentioned in the literature is a fire drill used for cauterization. In other countries such as Bavaria and Hungary, graves from the La Tène Iron Age (400-200 B.C.) contained various retractors and saws, but of hypothetical use only. Perhaps the most intriguing evidence that amputations were performed in ancient times is a Roman artificial leg with a wooden core and bronze overlay ${ }^{[2,4]}$.

\section{Animal pathological sources in antiquity}

Investigation of ancient disease patterns in animals depends basically on the same two sources as those for humans, i.e. remnants of former living animals and descriptions of diagnosis and treatment of diseases from written accounts, art forms and artifacts of ancient cultures.

Unlike its human counterpart, there has been very little study of animal diseases in antiquity, and although there have been many reports on bone, the majority omit any mention of pathological features. The aim of most of the reports on bone appears to have been solely the identification of the animal species.

Pathological lesions have been observed in animal bones, although the 'diagnosis' of the disease responsible for them remains debatable in most instances.

Possibly the oldest recorded fracture is that of the radius of a Dimetrodon-a Permian reptile (228-275 million years ago) - but there are many lesions throughout the ages which are regarded as showing fractures and healing. The results of bone changes due to inflammation such as osteitis, periostitis and osteomyelitis have been noted in a variety of species including cave bears of the Pleistocene period (100,000 to 1 million years old) and a mosasaur from the Cretaceous (70140 million years old) of Kansas ${ }^{[1]}$.

Arthritic disease is not apparently modern but appears responsible for many bone and joint lesions, as evidenced in dinosaurs, mosasaurs, Eocene mammals (40-70 million years old), a Miocene (11-25 million years old) crocodile, a Pliocene camel (1-11 million years old) and a number of Pleistocene mammals. 
Not all the observations have come from excavations, because some mummified apes (baboons) recovered in Egypt are thought to demonstrate rickets (a disease not found in man in this area). More modern thought points towards the occurrence of osteomalacia/osteoporosis, which is known to be common among captive animals.

Further pathological changes have been noted in the skulls of animals, and include among others inferior protrusion of the lower jaw of an early Peruvian dog (malocclusion) to varying dental deformities present in a Pleistocene peccary, a Mastodon molar and a fossil Rhinoceros. An early Egyptian baboon displays malnutritional alterations of the facial skeletal structure, and there are many examples of attrition, cysts, periodontal disease, odontoma and caries in cave bears as far back as the Pleistocene.

The second source of pathological information reveals an emphasis on the disease patterns demonstrated by animals directly linked to the needs of man. There are numerous ancient documents, carvings and art work covering the whole period of man's activities and varied cultures, sparse in the early phases and voluminous in the later phases. These form a series of recorded observations underlining the man-animal interaction while describing the various diseases and treatments.

Written records do not present a single uniform beginning relative to animal diseases, and therefore pathology, because only small parts of the documents and tablets deal with animals. However, some documents are outstanding, such as the Gaja Sastre (a Sanskrit collection), and there is also the Rig-veda (20th-15th centuries B. C.) and the Upanishads (16th-9th centuries B. C. $)^{[1,2,5,6]}$. A later source is the Babylonian Code of Eshnunna (1900 B.C.) which recounts the recommendations for the removal of horns - a surgical expedient to prevent the infliction of damage. Interest in animal medicine also surfaced in Egypt through the writings of the Kahûn Papyrus (1800 B.C.) together with other sources, such as the Babylonian Code of Hammurabi (1750 B. C.), various Hittite texts and references made in the Bible and Jewish Talmudic scriptures.

The basic reason for the rise of interest or frequency of written accounts on animal diseases can be ascribed to the appearance and development of animal domestication. Domestication of animals can only be defined by viewing animals in their most developed form, noting that there are four main characteristics: their breeding is under human control, the animals are tame, they provide a service or a product useful to man, and they have been selected away from the wild strain. Only with this modern endpoint can it be realized that the "domestication" of animals through the ages shows a long and tortuous path of change.

Animal husbandry probably started with the goat some time before 7000 B. C., probably on the slopes of the Zagros mountains (Iraq-Iran border), but the earliest remains have been found at Asiab on the Iranian plateau dating from about 8000 B. C. Domesticated goats appeared in Palestine in the 7th millenium B. C., in Egypt in the 5th millenium B.C. and in Mesopotamia in the 4th millenium B.C. Eventually this practice spread to western Asia via the dual routes of Afghanistan (to Mongolia and northern China) and the Khyber Pass (to India and southeast 
Asia $)^{[8-10]}$.

The emergence of domesticated cattle in Anatolia - the longhorn type occurred around 7000 B.C., while their replacement stock - shorthorns originated in Mesopotamia around 3000 B. C.

Sheep domestication appears to have occurred very early, from bones found at Zawi Chemi Shanidar (Iraq) dated 9000 B. C.

Camels as a group can be divided into the two-humped and one-humped types. The two-humped camel underwent slow domestication on the borders of Turkmenistan and Iran around 2700-2500 B.C. Its one-humped counterpart underwent domestication during the period 3000-2500 B. C. in what is now known as Yemen.

The ass was first domesticated in northeast Africa, and there are many Egyptian records and remains from around 4000 B.C., while a little later they appeared in Asia.

The earliest taming of the horse was in the southern Ukraine around 3500 B.C., spreading thereafter to western Europe in 3000 B. C. and to Greece in 1900 B.C. Elsewhere domestic horses also spread to Mesopotamia and other regions of the Near East around 3500 B. C. ${ }^{[8-10]}$.

Introduction of the pig to the domestic scene is thought to have occurred in Anatolia around 7000 B.C.. In addition, there is evidence of its presence in the Indus valley civilization around 2000 B.C., and in China where finds have been complemented with carvings of cult vessels and cultic pillars of the Shang epoch (1766-1123 B.C.) indicating pig usage ${ }^{[3]}$.

Water buffaloes were initially domesticated in Mesopotamia during the Akkadian dynasty and/or in the Indus valley civilization of Harappa and Mohenjo Daro before 2500 B. C. There are very few finds, but information has been noted on cylinder seals from the Akkadian period of ancient Mesopotamia, which indicates a domestication date of 2350-2150 B. C. Malay immigrants are thought to have been responsible for taking the water buffalo to the Philippines around 300-200 B. C.

As a natural sequel to domestication of animals, men have been recorded as being directly involved in animal health from texts emanating from some Greek states around 500 B.C. - the beginnings of veterinary medicine. The history of animal disease is found in the writings of Hippocrates (430-330 B.C.) and later those of Xenophon (390-345 B.C.). Aristotle (384-322 B. C.) built up a remarkable series of writings covering anatomy, zoology and tracts on a large number of animal diseases of the time.

Viewed as a whole up to this point, the disease patterns described were many, varied in degree, and accounts differed in accuracy, and therefore were very difficult to use as a basis for diagnosis or applied treatment. As a medical science, it was distinctly unsatisfactory and eventually culminated in a search for new standards. The emergence of new standards is attributed to the Romans, and described in the texts of Vegetius, Varrow, Columella and Celsus among others. In the latter part of the 4th century A.D., Vegetius began the process by writing a lengthy treatise on horses and mules - the much acclaimed "Mulomedicina", and 
this heralded the beginning of new trends in animal disease diagnosis, treatment and husbandry.

With such advances in approaches to animal medicine through the Greek and Roman eras came a wider and deeper understanding of the disease problems, from which emerged considerable insight into the underlying pathology.

\section{The rise of oral pathology}

Prior to discussing the ancient links of oral pathology relative to man and animal, it must be emphasized that oral pathology as a fully recognized discipline only emerged in the first quarter of this century. History shows that its emergence stemmed from parallel developments in Europe and North America. In comparison with general pathology, oral pathology lagged behind by some 80 years as a slow-growing and late-maturing discipline.

The reasons for this late development are partly due to the state of knowledge of medicine and general pathology, which was gathering momentum, and the fact that dentists over a very long period taught their discipline as a craft, and not as a healing art and science. Dental philosophy and application were therefore confined to the identification and treatment of diseases of the teeth and their direct sequelae-basically the repair of teeth, the removal of teeth beyond redemption and the construction of prosthetic replacements.

Two factors among others are probably responsible for the expansion and deepening of the subject as it is known today. First, as demands for further understanding increased, more importance was attached to oral anatomy and histology, and secondly, there was increased awareness that a knowledge of pathologic processes and tissue changes at the cellular level is an essential basis of good medical and dental training. Reasoned pressure increased within dentistry, culminating in the acceptance of general pathology courses in the curriculum, supported at a later date by medicine and pharmacology courses. Oral anatomy, embryology and histology continued to develop, and histopathology gradually emerged as an additional field. In time, histopathology separated and formed a new discipline and the whole field then underwent change, broadening to include local diseases of the soft tissues of the oral cavity and jaws to lesions in the mouth caused by systemic diseases.

During this period of maturation it is interesting to note that the European dental institutes pursued their educational programs with a large element of scientific investigation of mainly the pathologic kind in order to clarify the pathogenesis and the reasons for the specific treatment of the diseases examined. In the same period, schools in North America were still emphasizing the importance of mechanical training.

With the establishment of oral pathology as a subject and the expansion of recognition and understanding of the diseases, the bases of new specialities of periodontics, endodontics and oral medicine were formed together with a general upgrading of dentistry as a whole. Hence oral pathology is clearly the most important science in which to make advances in diagnosis, treatment, and the subsequent prevention of dental and oral diseases. 
Comprehension of the full range of disease currently accepted within the spectrum of oral pathology is difficult to envisage when compared to the practical dental approach of the past. Diseases now considered are not only many, but involve a number of intricate disease classifications in differing fields. Hence within the overall categories or subjects there are inevitably diseases which, because of their inherent composition and etiology, can be placed under more than one heading. It can be said that there is no perfect textbook classification covering oral pathology, and even the simpler texts do not show clear subject continuity.

The most comprehensive classification is that published by the World Health Organization in Geneva, "Application of the International Classification of Diseases to Dentistry and Stomatology" (ICD-DA, 2nd edit. 1978). This classification is a direct extract from the International Classification of Diseases (ICD-9 WHO) including diseases and conditions that occur in, have manifestations in, or have associations with the oral cavity and adjacent structures.

The following list of diseases (reprinted from the ICD-DA) outlines the systems involved and provides an indication of the range within oral pathology, while leaving out specific disease details:

I Infectious and parasitic diseases

II Neoplasms

III Endocrine, nutritional and metabolic diseases, and immunity disorders.

IV Diseases of blood and blood-forming organs

V Mental disorders

VI Diseases of the nervous system and sense organs

VII Diseases of the circulatory system

VIII Diseases of the respiratory system

IX Diseases of the digestive system

$X$ Diseases of the genitourinary system

XI Complications of pregnancy, childbirth and the puerperium

XII Diseases of the skin and subcutaneous system

XIII Diseases of the musculoskeletal system and connective tissue

XIV Congenital anomalies

$\mathrm{XV}$ Certain conditions originating in the perinatal period

XVI Symptoms, signs and ill-defined conditions

XVII Injury and poisoning

Differences of opinion exist as to the place of oral pathology relative to general pathology. One outlook considers that oral pathology cannot be properly viewed as a segment of general pathology because the latter is applied to both the living and the dead, while oral pathology is linked to the living. However, the more prevalent opinion favors oral pathology as a speciality within general pathology. This premise is based on the fact that there are no essential differences between most of the pathological changes which occur in the oral region and analogous changes in other parts of the body. It is accepted that certain features of the basic processes may be evident to various degrees in diseases of the oral region. In addition, some pathological manifestations in the mouth may not have a 
counterpart elsewhere in the body. Diseases of this type which are linked to specific oral structures such as the teeth and adjacent tissue, will reflect as caries, periodontitis and their sequelae. In addition, there are also odontogenic neoplasms and developmental disturbances which are specific to the oral region.

\section{Oral pathology of ancient animals}

The available evidence of oral pathological disturbance in ancient animals is severely limited both quantitatively and qualitatively but provided by both wild and domesticated species. With the steady increase of the human population there has been a parallel increase in the use of domesticated animals for many purposes. It is thus a reasonable expectation that over time, domesticated animals would provide larger and more accessible concentrations of bones and teeth as study materials ${ }^{[1]]}$. However, the study of domestication of animals has been shown to be severely hampered by a lack of knowledge concerning the biology of the various species together with sparse and often inadequately reported specimens from excavations. In simple comparative morphology of bone, for example, changes may not be all attributable to human influence because it is known that many wild species have shown rapid changes in size alone. A domesticated animal used for draught purposes may well develop greater bone size and muscle/tendinous attachment areas which could be confused with its wild counterpart. At least part of the answer is to obtain contemporary deposits of true wild species in addition to those excavated from domestic sites in order to make comparisons.

Disease is the result of a complex interplay of causal agents, hosts and environment. The diseases currently accepted as falling within the sphere of "oral pathology" have already been shown to be extensive and those which leave a demonstrable alteration of morphology and structure in the hard tissue of the craniofacial region may, logically, be expected to be manifest in ancient material. In relation to this, it must be remembered that as in humans, animal life was probably shorter, and some of the hard tissue diseases known today are linked to age, some diseases are rare and do not occur in animals while others may be the province of animals alone. Further to this is the lack of samples for investigation. The final result must be the confirmation of the more common hard tissue diseases with only odd and often debatable examples of other currently known diseases.

Evidence of pathological lesions in bones and teeth of ancient animal populations is sparse and provides a very limited representation of the pathological range embodied in the current classification of oral pathology.

Examination of one particular branch of the classification - that of congenital defects (non-inherited)-shows that the mental foramen of the mandible varies in size and number, and mandible fragments have been excavated showing a relatively large mental foramen and also duplication and triplication in bovine species. A further abnormality is the presence of often large and multiple holes in the posterior areas of bovine skulls. It is interesting in relation to the dental field that these holes communicate with the posterior of the frontal sinus. A final rare example emerges from the remains of a prehistoric dog from Mexico which displayed abnormalities of the atlas and axis, which were fused together, and a 
very large foramen magnum. These features bear a close resemblance to the Klippel-Feil syndrome.

Congenital defects possibly linked to genes and breeding have also been found, with examples such as the Peruvian dog with mandibular protrusion and malocclusion of the teeth. There have been many observations of partial anodontia, and retained deciduous and supernumenary teeth. One of the earliest finds of supernumerary teeth was noted in a Pleistocene dog (Canis dirus).

Then there are developmental disturbances of unknown etiology which can influence both jaw and tooth morphology ${ }^{[12]}$. Abnormally formed third molars have been noted in a number of deer, while the outstanding example always quoted is that of the malformed crown of a Mastodon molar from the Pleistocene period.

Developmental problems also include some of the irregularities noted in dentition, such as malocclusion, tooth alignment, tooth impaction, rotated teeth and even angulation problems ${ }^{[12]}$. These have all been observed through the various eras and periods of antiquity and are known by some characteristic examples such as the fossil Rhinoceros with a malpositioned premolar and a retained deciduous tooth. There are also impactions of posterior mandibular teeth of prehistoric Bison from America, overcrowding of teeth in sheep mandibles from Roman Britain and an unusual example of rotation without crowding in a peccary (Mylohyus nasutus) from the Pleistocene period.

Bone can undergo inflammation, and depending on its starting point can be recognized as osteoperiostitis, osteomyelitis and osteitis, although the speed of events may mean that these are not diagnosable as distinct entities. In pathological specimens from antiquity it is difficult to be positive in the final assessment. Non-specific infections usually gain access to bone from infected tissue nearby, middle ear infection, infection of the sinuses as seen in a Pleistocene musk-ox, the result of horn polling of cattle and spread of rhinitis. In addition there is the oral path to bone through tooth and mucosal damage and their sequelae.

Osteomyelitis has been found in a number of bones from many sites, and in the oral pathology field its presence relative to tooth socket infections has been found in some of the later periods. A pig mandible from the Mesolithic period together with other mandibles of sheep from pre-Viking and Viking levels are examples. The other types of inflammation-osteoperiostitis and osteitis-have not been found with certainty in the craniofacial region.

Specific infections of bone such as Actinomyces bovis (lumpy jaw of cattle) produce a form of osteomyelitis, so that diagnostically an excavated bone will be difficult to assess ${ }^{[13]}$. The disease has been attributed to the cave bear and to an Apholeps rhinoceros from the Miocene period, and recently to Anglo-Saxon bovine specimens.

Malignancy of bone has appeared very little in the records of antiquity and perhaps the only one in the oral pathological field is the osteoma in the skull of a horse of unknown origin or date.

The effects of nutrition, especially those with an influence on bone, can produce a spectrum of alterations from rickets to hyperparathyroidism. 
A mandible derived from a baboon in Egypt was found to display porosity of the bone with some expansion, and has attracted various diagnoses. Current thought regards this phenomenon as a long-term dietary imbalance.

Caries as a disease is not especially characteristic of the animal world but it does occur particularly in some of the domesticated species. The presence of caries has been claimed for cave bears in the Pleistocene period and so far this has been accepted. What is still open to debate is the "caries" of a Mastodon, which may well be ante-mortem decay. In Roman Britain a sheep mandible has been found showing a swelling due to chronic inflammation of the roots of the teeth. Further examples of pathological change linked to caries and abscess formation have been found in both the Roman and Anglo-Saxon periods.

Periodontal disease in ancient jaws is manifested by receding alveolar margins, pockets forming between the teeth and very loose teeth. This disease appears to occur mostly in domesticated animal groups, particularly sheep and pigs whose food might be limited by overgrazing, poor supply of winter needs and general poor animal husbandry ${ }^{[14,15]}$.

Cysts and abscess in bone are difficult to assess, but cysts are usually larger with denser rounded margins. Many of these have been found in animals mostly of the domesticated type ${ }^{[16]}$.

Excessive attrition for a great number of reasons such as partial anodontia, premature loss, breakdown or trauma can occur in animals. The results of such attrition can lead to pulpal exposure and infection with eventual apical abscesses. A very late example of this type of development can be seen in a hyena jaw from Derbyshire. Human contrived attrition has been revealed following excavation of the earliest known true horse ever found on an Egyptian site. This occurred at the fortress of Buhen (erected around 2000 B.C.), where the remains of a 19-year-old horse manifested a pattern of tooth attrition only possible by use of a bit. A further discovery at an Iron Age burial ground (Magdalenska Gora, central Europe) showed similar attrition on horse teeth.

Another rare hard tissue formation linked to development of teeth is odontoma, which can be regarded as a hamartomatous malformation rather than a neoplasm. In other words, it consists of a normally formed tissue, but in irregular quantities. One type of odontoma consists of many small tooth-like bodies while another is represented by an irregular mass of calcified tissue. One massive odontoma has been found in a horse of the Gallo-Roman period, and a much smaller one has been recovered from a camelid in Ecuador.

At this juncture, it must be pointed out that the abnormalities and diseases described within the limits of the oral pathological field only represent a fraction of paleopathology found in the rest of the skeletal system of animals. A number of these would be manifested in the oral region, but so far have not been identified.

\section{Oral pathology of ancient man}

\section{Caries}

It is ironic indeed that during the lifetime of man, decay and disintegration of his dentition stand in marked contrast to its ability to withstand destruction after 
death for thousands of years. Dental decay or caries, as we have already seen, is not the province of man alone but occurs in animals, so that both have suffered pain, abscesses and tooth loss but of variable degrees, since animals show a reluctance to join man in his liability to tooth disease $\mathrm{e}^{[2,4,14,24]}$.

Manifestations of dental caries have been confirmed and traced back to the earliest known, unequivocal, hominid Australopithecus, a genus that lived some 1.5 million years ago in the Early Pleistocene period ${ }^{[17,18]}$. Australopithecus can be regarded as a single genus with a number of species or local varieties, and was located in South Africa, northern regions of the African continent and possibly eastern parts of Asia.

Next in the evolutionary succession of man is the ancient hominid genus Pithecanthropus, which existed in the Early and Middle Pleistocene period (500,000-200,000 years ago). A number of skeletal remnants were found in Central Java (Indonesia) ${ }^{[20]}$ and at the Chinese village of Chou Kou Tien ${ }^{[3]}$. In addition, further remnants have been excavated in Algeria and East Africa. Dental caries has been confirmed in the teeth of one of the Javanese skulls.

The next phase of man's evolutionary progress enters a grey zone, which is often referred to in its cultural settings because of uncertainty. The main cultural group is that known as the Mousterian ${ }^{[19]}$ and this can be subdivided into Pre-Mousterian (200,000-100,000 years ago), the Early Mousterian (100,000-70,000 years ago) and finally the Late Mousterian (70,000-40,000 years ago), the later phase being regarded as the period of Neanderthal Man.

The Pre-Mousterian period has a very meager fossil record mainly based on assumptions derived from the Steinheim skull (Germany), and fragments of skulls found at Fontéchade (France) and Swanscombe (England). These are thought to show very early links with Homo sapiens skull characteristics. No caries have been observed.

The Early Mousterian period has provided a number of fossil remains both in Central Europe and Israel. The remains have a very wide variability of characteristics as shown from the Tabun and Skhūl Caves at Mount Carmel in Israel. The Tabun finds show typical Neanderthal Man characteristics, whereas those obtained from Skhūl have many facets of Homo sapiens or Proto-Crô-Magnon Man. Evidence of caries has been found in the Proto-Crô-Magnon group from the Skhūl Cave.

Neanderthal Man (Late Mousterian period) was first found in the valley of Neanderthal near Düsseldorf (Germany), and revealed definite skull characteristics which seemed well removed from those of Homo sapiens. This group appears to have been confined to Western Europe before being replaced by a more modern type (Homo sapiens) probably from the Middle East. However, in addition to this group, there was another consisting of Neanderthal-like men who appeared to be variants. These were located in Asia and Africa and were exemplified by Solo Man (Java), Saldanha Man (South Africa) and Rhodesian Man (Central Africa). These equivalents of Neanderthal Man in Africa were eventually replaced by more adaptable variants of Homo sapiens ${ }^{[17,18,21,22]}$.

In terms of dental disease, Rhodesian Man is of specific, if not isolated, 
interest because in the 13 teeth available, 11 were found to be carious with a total of 15 cavities in addition to two fractured teeth and a number of chronic abscesses $^{[4]}$. In the European Neanderthal group, however, in spite of a much greater number of teeth available, no carious lesions have been found.

The earliest evidence confirming the replacement of Neanderthal Man in Europe was the fossil from the Crô-Magnon shelter at Les Eyzies, Dordogne (France), hence the term Crô-Magnon Man. This type was found to consist of several variants such as the Combe-Capelle (Dordogne), the Grimaldi (Liguria, Italy) and the Chancelade (Dordogne) in addition to Crô-Magnon. Over the period of 40,000-10,000 years B.C., various cultures emerged involving the CrôMagnon group, and these were identified in chronological order as the Aurignacian, the Solutrean and the Magdalenian. The presence of carious teeth has been noted in Aurignacian and Solutrean skulls.

In general terms, the next major cultural division is that of the Mesolithic, which consisted of hunter-fishers and gatherers over the peroid of approximately 10,000-3,000 years B.C. in both Europe and Africa. By the time the glaciation began to retreat in Europe around 8300 B.C., man had already spread further by crossing the Bering Straits land-bridge into Alaska, moving through the grasslands of North America and the western margins of South America, eventually to reach Australia by a circum-Pacific route. At the start of the Post-glacial phase, Britain was still part of the European continent until the rising waters flooded over the now southern part of the North Sea around 6000 B.C. Prior to this separation, a major Mesolithic site was founded at Star Carr (England) by the Maglemosians from Denmark. Thus the 9th millenium saw environmental changes in which economic and social adaptations arose in response to the altered landscapes, the higher temperatures, the spreading forests and the flora and fauna.

The shift from the hunter-fisher-gatherer society to a cereal-based society gradually emerged between 7000 and 5000 B.C., probably from the Middle East. The period within the boundaries of the Mesolithic culture and its hunter-farming communities is an example of post-glacial adaptation.

From skulls and mandibles of Mesolithic sites in Europe and Africa carious lesions have been noted, with indications of an increased incidence in the later half of this period. In Europe, a higher caries rate was found in teeth excavated from Ofnet in Bavaria and from Téviec in Brittany.

European dental decay is often quoted as being synonymous with the occurrence of the "Neolithic Revolution", and it does appear from the records that the frequency of caries increased significantly during this period.

The Neolithic culture (New Stone Age) stemmed from Middle Eastern origins around 7500 B.C. and gradually spread until it had established itself in northern Europe and Britain by 2500 B. C. It appeared in South Asia (Pakistan, India) ${ }^{[6]}$ as early as 5100 B.C. in one area, but later in others, and also reached China. In its most simplistic definition, the "revolution" was a shift of emphasis from a hunter-fisher-gatherer economy to a food-producing economy by means of agriculture and animal husbandry.

To give perspective to this new culture, it must be realized that the three great 
cereal regions of the world are based on the cultivation of wheat, rice and maize. In the Near and Middle East, wheat and barley emerged first, followed by rice and millet in southern and eastern Asia and finally by maize in Central America. Other crops were 'farmed' in these regions, including pulses, oil-producing plants like flax, fruit, sweet potatoes, sunflower seeds and tomatoes ${ }^{[23]}$. The evolution of the Neolithic culture continued for some time in each of these three regions as separate and independent groups and it was only much later that some degree of exchange occurred in agricultural developments. Domestication of animals spread from the Middle East in a parallel development to agriculture, the species involved including dogs, goats, sheep, cattle and pigs, all of which were part of the Old World $^{[8-10]}$. In the New World, domestication also took place, as represented by the North American turkey, and in South America by the guinea-pig and a camelid (the guanaco) from which the llama and the alpaca are thought to be derived $^{[10]}$.

With the gradual development of farming, the mode of life began to change to a more settled type with a phasing out of nomadic elements. One of the direct results of this was the forming of conditions suitable for specialized craftsmen and the establishment of traders. The expansion of the Neolithic culture was due to a rise of population and the "slash-and-burn" cultivation method which inevitably led to soil exhaustion and the need to migrate. This problem was not widespread, since areas such as Jericho and the Nile Valley renewed and retained soil nutrients by irrigation and by using the flood plain, respectively.

Cultural expansionism over many land regions inevitably incurs time-span differences, and while the Neolithic practices were active in the Middle East, the rest of Europe remained Mesolithic. When the Neolithic late phase was established in northern Europe, the Bronze Age was current in the Middle East. In summary, the Neolithic phase is known to have covered the period of approximately 75003000 years B.C. in the Middle East, while in Britain the active phase lasted from 2500-1800 years B.C. Similar differences occur elsewhere in the world, and the Polynesians provide a good example by being culturally Neolithic when they reached New Zealand around 1000 A.D.

From the dates available, it is evident that Neolithic agriculture and animal husbandry must have existed in some form within the Mesolithic period of 10,000-3000 years B.C. In addition, the frequency of caries obtained from Mesolithic sources was found to be higher than most of the populations within the Neolithic period of 3000-10,000 years B.C. An inference can be drawn that the Mesolithic or Pre-Neolithic incidence of caries may have been linked to early Neolithic agricultural practices and hence diet. However, within the main Neolithic cultural phase, the lower frequency of caries often found is in contrast to the popular belief of the role of the Neolithic diet. Evidence supporting this has emerged from various Neolithic populations examined for the period 3000-1000 years B.C., composed of French, German, Swedish, Danish, British and Predynastic Egyptian-all having lower caries frequencies than those of the Mesolithic period with the exception of Greece. Elsewhere, the population of Crete (17501550 B.C.) shows a higher figure, while another population sample from China 
(1766-1112 B.C.) shows a low figure. The idea of cereal cultivation and dietary refinement as a basis for increased caries fits modern concepts, and in the absence of another explanation for the lower frequency of caries found in the mainstream Neolithic period relative to the Mesolithic, it can be tentatively postulated that the migrational practices arising out of the "slash-and-burn" agricultural policy together with related dietary changes may have been responsible for the phenomenon.

The sequence of cultures which follow involves the Bronze Age, the Iron Age and, in Western Europe, the Roman civilization. These cultures all demonstrated considerable overlaps with one another, but the total time period for all of them lies around 2300 B.C. to 400 A.D. Carious lesions found in these cultures show a general increase in frequency, but with considerable fluctuations. In Europe, based on populations from Greece, France and Britain, a larger fall in frequency occurred around 400-600 A.D. followed by a steep rise. There are two possible factors responsible, firstly the decline of the Roman Empire with turbulence making farming difficult, thus causing dietary changes and caries reduction, and secondly, the steep rise of carious lesions could be linked with the production of more refined sugars and flours, which appeared after 600 A.D.

\section{Periodontal disease}

Periodontal disease has proved more difficult to identify in antiquity because, of the periodontium, only the osseous part remains intact. Diseases which influence the health of the periodontium consist of inflammatory, degenerative and neoplastic ones in addition to atrophy related to advanced age. Observations of bone loss or alteration are usually manifest by a retreat or recession of the marginal alveolar bone (Fig. 2). Chronic inflammation of the alveolar crest exhibits a porous bone at the interproximal septa and crenation along the facial and lingual aspects. The main difficulty lies in separating osseous changes which could arise from either physiological or pathological causes.

In the Old World, evidence of periodontal disease, based on alveolar bone resorption, has been reported in a number of Neanderthal specimens. These were mainly young, since very few mature or aged skulls have been found. The skulls originated from excavations at La Chapelle-aux-Saints (France), Kaprina (Yugoslavia) and Rhodesia among others ${ }^{[1,2,4,14]}$. Further finds in European Mesolithic and Neolithic populations reveal that young dentitions very rarely show alveolar bone loss, whereas in adult samples over the age of 30 years there are superficial signs of alveolar bone change attributable to gingivitis. In the much older individuals, alveolar bone loss varied from mild to severe. In later periods such as the Bronze and Iron Ages, the Roman period and the following Anglo-Saxon period, the degree of alveolar marginal resorption showed an increase, possibly due to refined diets.

Periodontal disease also existed outside the Old World, and ancient skulls from Guam show that all of the women and most of the men suffered from this problem. The habit of betel-nut chewing is a possible source, since the use of lime enabled considerable deposits of calculus to occur with attendant inflammation. 
Similar circumstances have been noted in pre-Columbian Peruvian skull remains derived from mummies, where there was a high loss of teeth and alveolar destruction. The Peruvian diet was relatively well balanced, but each mummy had a small bag around the neck containing coca leaves (Erythroxylon coca), which was chewed with a substance known as Ilute made from shells and ashes of plants containing alkali. The resulting use probably caused considerable damage to the periodontium, since it is known that cocaine alkaloid can induce necrosis in tissues $^{[2]}$.

\section{Tooth attrition and pulp exposure}

Attrition of the tooth surfaces is a characteristic of all humans throughout all periods, but in its marked form it lies within the province of ancient man and modern primitives. Essentially, attrition is the wearing away of tooth enamel, and eventually dentine, during mastication by the rubbing of one tooth surface against another. The degree of attrition achieved depends on the amount and strength of mastication in addition to any abrasive material included in the food. There are slight differences in the amount of attrition between males and females for cultural and physical reasons, to which can be added the effects of age.

Usually attrition remains limited in the young, but after the age of 30 years it becomes visible and eventually becomes very marked in the aged. Continuous attrition of the dentition leads to larger areas of dentine exposure, activation of secondary dentine repair, and eventually, in many instances, exposure of the underlying pulp chamber with the sequence of infection, inflammation and necrosis of the pulp tissue. Breakdown of the pulp may lead to chronic abscess formation (periapical), leading to a cyst, both of which may revert to an acute state with loss of the tooth.

From the earliest forms of man it is evident that caries, periodontal disease and attrition have been present, and in terms of human problems they are immeasurably ubiquitous to the point that few have escaped.

Exposure of tooth pulp through excessive attrition has been found in material derived from Neanderthal Man through the Mesolithic and Neolithic cultures together with the Bronze and Iron Ages and beyond. One especially interesting example is the Egyptian period of Predynastic to Early Christian (3000-500 B. C.). Prior to 3000 B.C., pulp exposure due to attrition appeared to have been the prime factor responsible for the occurrence of periapical abscesses and possible tooth loss, yet the caries level was known to be low. In the Egyptian populations the early phase showed a fall in the frequency of pulp exposure and abscess, and this was followed later by a rise in the occurrence of abscesses ${ }^{[24]}$. In conclusion, it appears that the exposure of pulp by attrition was mainly replaced by an increase of caries related to diet alterations and an additional rise in the incidence of periodontal disease.

\section{Periapical abscess and cyst}

Chronic periapical abscesses have been reported for all the periods of antiquity including Rhodesian Man (originating from caries) and Proto-Crô-Magnon 
Man from the Skhūl Cave in Israel (originating from periodontal disease). In its mature form, the chronic periapical abscess shows a spherical-shaped area of bone destruction at the root(s) of a tooth, inferring that the pulp tissue has died due to exposure by attrition or caries, the crown has been fractured or received a blow, or periodontal disease has spread down the periodontium of the root. Whatever the cause, an area of bone has been lost, but it is impossible to judge whether the bone loss represents a dental cyst or a chronic periapical abscess (Fig. 3)

Other bone cysts occur in various parts of the craniofacial region, some of odontogenic origin and others from non-odontogenic sources. Many of these are fairly large and in the reports to date, cystic lesions have had direct links with tooth problems. Among the accepted cysts are those found in ancient Nubian and Egyptian material together with a very large example from a pre-Columbian Peruvian skull ${ }^{[2,4,25]}$.

\section{Hypercementosis}

In the root area, there is a distinct possibility that problems with the dentition of ancient man could be reflected by hypercementosis. This is the deposition of excessive amounts of cementum due to a number of factors ranging from low-grade infection of the tooth to severe attrition. Evidence of hypercementosis has been observed in Neanderthal Man from three specimens (Gibraltar I, Monsempron, Ferrassie I) all linked to attrition, while examination of Rhodesian Man and others show early hypercementosis thought to have arisen from infection ${ }^{[14]}$.

\section{Absent and anomalous teeth}

Disorders of oral structures may be prenatal or postnatal in origin, and may be inherited or acquired. A congenital disease is one which occurs before or at birth but is not necessarily inherited, while a number of hereditary states are found at birth or become evident over a number of years. Naturally, the known types of developmental disorders manifested in teeth and bone can only be sparsely represented in samples from antiquity.

Manifestations of disturbances in tooth number include anodontia (absence) and supernumerary (additional). Congenital absence of teeth is therefore known as anodontia, hypodontia or oligodontia and is usually demonstrated in a partial form rather than the rare total form. Partial anodontia has been noted throughout the various periods and cultures to the present day. Various individual teeth can be missing anywhere in the dentition, but there appears to be an emphasis on the absence of the maxillary lateral incisors, the premolars, especially the second, and the third molars. Third molar agenesis has not been reported in man up to and including Neanderthal Man but does appear in the Aurignacian groups and Mesolithic Man (Europe and North African) albeit in restricted numbers. In the Neolithic culture, particularly in Europe, there is an increased frequency of absence of third molars at a level which made that state relatively common.

Supernumerary or extra teeth occur in early man but then become rather unusual in the Neolithic period, thereafter increasing in the Gallo-Roman period and Middle Ages ${ }^{[14]}$. In summary, the evidence indicates that both partial 
anodontia and supernumeraries have undergone a slow progressive increase over time, with anodontia becoming more prevalent. Both states can occur in the same dentition.

The size and form of teeth are subject to genetic, developmental and posteruptive factors, of which heredity is probably the most important. Relative to fossil material, microdontia or teeth which are smaller than normal are usually very difficult to assess from the limited examples available. In contrast, microdontia involving a single tooth is clearly demarcated from not only the adjacent teeth but also its analogous counterpart in the maxilla or mandible. Certain teeth exhibiting a reduced size have been found in ancient skulls. Usually the tooth involved was the maxillary lateral incisor in the early populations, to which could be added the third molar in later populations (Fig. 2). The maxillary lateral incisor was often "peg"-shaped and examples have been observed from the Neolithic, Bronze and Iron periods up to the present time.

Another dental anomaly is the formation of a molar tooth in which the body appears to be enlarged to the detriment of the roots. This is known as a "taurodont". Tooth forms of this type have been found in Neanderthal Man and in fossils from other periods and cultures, but appeared most commonly in the Neolithic culture. Taurodonty occurs in both deciduous and permanent molar teeth. Modern examples exist in certain populations of South Africa and in Mongoloid people, but only a few have been found in Europe. The general consensus of opinion is that the more extreme forms of taurodontism occurred in fossil man.

\section{Tooth structural disruption}

Disturbances in tooth structure involve enamel and dentine, but as far as fossil material is concerned, the result of enamel disruption visible (macroscopic) on tooth surfaces is most accessible to immediate study. Enamel development has two distinct phases, firstly the formation of the organic matrix and secondly its mineralization. If either of these phases is adversely influenced, then hypoplasia or a defective enamel structure will ensue from the matrix formation; if the mineralizing mechanism is disrupted, hypomineralization will result. Irrespective of the type of disruption, the microstructure of the teeth is affected.

These disturbances may appear in a single tooth, a group of teeth or in all teeth, and both hypoplasia and hypomineralization are attributable to local, systemic or hereditary influences. The state of the enamel structure in terms of its extent and nature is related to the duration and degree of activity of the agent involved. Common local causes include infection and trauma, systemic causes involve metabolic factors (calcium, phosphorus and vitamin D deficiency; some abnormal Ca-P dietary ratios; rickets; hypoparathyroidism; vitamin A deficiency) and various exanthematous diseases of childhood, or congenital syphilis. Dentine response to these factors is more variable, and is characterized by increased or decreased deposition of various types.

Mild macroscopic hypoplasia is represented by a few small grooves, pits or fissures on the enamel surface. If more severe, then there may be rows of deep pits 
distributed horizontally across the tooth surface. There may also be a single row of pits or perhaps several rows indicating a number of injuries. In a very severe case, a portion of the enamel may be totally missing.

Enamel hypoplastic defects have been found in the teeth of the Australopithecine genus and Pithecanthropus. Various fossil remains of Neanderthal Man (Spy II and a child, Gibraltar II) show hypoplasia, and a faulty microstructure has been noted in a Proto-Crô-Magnon Man from Mount Carmel (Israel) ${ }^{[24]}$. Pits and grooves have been reported from the Crô-Magnon group, from finds in the Mesolithic cultures of Europe and North Africa and in later groups such as the Neolithic, Bronze and Iron periods. The study of hypoplastic anomalies is still in its infancy relative to antiquity, but there are interesting discrepancies already emerging from the frequency levels; for example, the Mesolithic period has a higher level than in earlier periods or cultures, yet a series from the French Neolithics has revealed very little evidence of enamel defects.

\section{Bone inflammation}

One of the most frequent bone problems emerging from antiquity arises from non-specific inflammation. This bone inflammation is normally classified as osteitis, periostitis or osteomyelitis, and can develop from dental infections and a number of organisms. In addition, these lesions can be caused by specific infections such as tuberculosis, treponematoses, leprosy and actinomycoses. The classification of non-specific inflammations presents difficulties, since the phenomena of osteitis, periostitis and osteomyelitis may lead to one another or may all be present at the same time. Non-specific inflammatory bone changes, irrespective of the particular terminology used, have been found in the bones of both man and animals and the evidence seems conclusive. However, evidence has been very difficult to find in the craniofacial region relative to oral pathology, although it is accepted that it probably exists. Rhodesian Man is known to have had dental disease and ear infections. Similar bone inflammations have been ascribed to Ancient Egyptian and Nubian remains, ear infections have been noted in Bronze Age and AngloSaxon Britain, while a Medieval skull showed alveolar fistulae and chronic sinusitis $^{[2,4,25]}$. An Egyptian skull found with a perforated palate claimed to be caused by rhinitis. In a sample of pre-Columbian Peruvians, a relatively large number of individuals over the age of 40 years had fistulae draining the maxillary antra. Chronic apical abscesses and cysts arising from caries, attritional pulp exposure and trauma have already been mentioned, leaving us with the controversial case of the bony fistula or "boring" of the Egyptian mandible of the IV Dynasty (circa 2500-2180 B.C.), which displayed two holes thought to represent surgical intervention in order to drain dental apical abscesses ${ }^{[2,25]}$ (Fig. 4).

\section{Tuberculosis}

Tuberculosis has been reported in some form at least as far back as 1300 B. C. and has been quoted in the Ordinances of Mantu (India). Later the disease has been referred to in the Sushruta Samhita (600 B. C.) in addition to records in China around the same time. In skeletal remains, lesions have been found from 
Ancient Egypt, Nubia and some isolated European recoveries. The New World also provides evidence from Peru, Venezuela and pre-Columbian specimens from the State of New York. All of these involve lesions of limb bones and spinal vertebrae, and the only representative which falls within the scope of oral pathology is a Neolithic group from Germany which displayed periapical osteotic foci which were postulated as being caused by tuberculosis, but which could easily have originated from another specific infection such as actinomycosis.

\section{Treponematoses}

The spirochaete Treponema causes a number of diseases known today as endemic syphilis, pinta, yaws and venereal disease. The tentative view considers that pinta (Treponema pinta), which causes a non-venereal infection, emerged in Central Asiatic tribes around 15,000 B.C. and probably passed to the North American continent by way of the Bering Strait land bridge prior to its severance. Later, it is thought that yaws (Treponema pertenue) arose in the Old World and eventually passed to Australia. Endemic or non-venereal syphilis (Treponema pallidum) is also thought to have evolved in the Old World around 7000 B. C. and was restricted mainly to the warm arid climates of North and South West Africa, and later Australia. This organism is thought to have caused a mild form of venereal syphilis around 3000 B.C., probably stimulated by the increase of urban living. This mild form of venereal disease appears to have lasted until the late 15th century A.D., when it appears to have been supplanted by a more virulent mutant, which produced the great European epidemic of severe syphilis. The coincidental return of Columbus from the West Indies has, inevitably, caused it to be linked to his seamen, but since the disease has been quoted in the Old Testament and in ancient Chinese writings, the Columbian origin is still in doubt.

Of these treponematoses, three are associated with bone lesions-yaws, endemic syphilis and venereal syphilis. In the Old World signs of syphilis in any part of the skeletal system do not appear until very late. In the New World a number of lesions have been reported, probably of both pre- and post-Columbian date, but the majority remain unproven. In the case of yaws, there appears to be evidence of prehistoric occurrence in the Mariana Islands and in pre-European Australia. In the more advanced phases of yaws, the hard palate may be destroyed and the nasal region attacked. Although there are specimens in some museums, they are all of more recent dates. One of these is that of a female Veddah (Sri Lanka), which shows bone destruction of both the palate and nasal region ${ }^{[2,4,25,26]}$ (Fig. 5).

\section{Leprosy}

Leprosy is a chronic granulomatous disease caused by Mycobacterium leprae and currently occurs in Asia, Africa, Central and South America and Oceania. Two basic types of lesion affect bone, firstly lepromatous leprosy which spreads to bone from dermal or mucosal lesions - usually of the hands and skull. Secondly, tuberculoid leprosy which involves peripheral nerves resulting in marked atrophy of bones initially in the limbs, thereafter moving in a proximal direction. In short, 
the disease is manifest in the bones of the face, palate and extremities. Direct bony evidence of leprosy is limited to historical times, since a study of more than 18,000 skeletal remains reveals no signs of the disease until the 6th century A. D. However, written records indicate that there were special segregation houses set aside for 'lepers' in the 4th century A.D. Recently the movement of leprosy through northern Europe by late Roman times has been confirmed from skeletal evidence dated the 4th century A.D.

In written evidence are descriptions of diseases similar to leprosy in the Sushruta and Charaka Samhitas (600-400 B. C.) of India in addition to the Huang Ti Nei Ching (100 B.C.) of China ${ }^{[2,3,4]}$. Quotes from the Old Testament regarding leprosy have been noted using the word "zara'ath", which covered a number of different skin diseases but which probably resulted from a mistranslation from Greek texts. The current term leprosy originated from the Greek word lepra (lepros, scaly), which was applied to all kinds of scaling skin disease including psoriasis, leucoderma, impetigo and ringworm. On the other hand, the Greeks were aware of leprosy and described it by means of the word "elephantiasis" which ably described the thickening and corrugation of the skin. In time, irrespective of this clear distinction, the term "lepra" has become accepted as the official medical term for leprosy. Identification of the numerous ulcerations and skin lesions resulting from true leprosy is, therefore, impossible from the records, but this and the late appearance of direct bone evidence must not be considered to point to a new disease-it has been with man for some time.

Artistic evidence varies, but a pottery grain storage jar, Canaanite in origin from Amenhotep III temple, Beth-Shan, Jordan (1411-1314 B.C.) bears a face showing features very closely akin to those of lepromatous leprosy ${ }^{[2,4,25,26]}$.

Bone changes in leprosy have been clarified from Danish Medieval skeletal remains and it is now known that the disease was present in the 6th century A.D. in Egypt, France and Britain, and that more recent recoveries and identification have pushed the period back to the 4th century A.D. The information gleaned from Danish skulls now provides a clear picture of the bony changes associated with the disease. These include atrophy of the alveolar bone around the upper incisors, the presence of minor osteitis in the hard palate or loss of whole areas, the reduction or absence of the nasal spine together with an interesting reaction of childhood which produces tooth malformations especially in root growth (odontodysplasia leprosa) (Fig. 6).

\section{Hard tissue tumors}

Tumors of the hard tissues are not only uncommon in ancient man but are very difficult to interpret, and those of the orofacial region are very few in number. Bones may reveal neoplastic change by the formation of bone (osteoblastic neoplasm), or by its destruction (osteolytic neoplasm), but a decision as to whether lesions are benign or malignant presents considerable difficulty especially when pseudopathological postmortem changes simulate osteolytic neoplasia or when postmortem decomposition removes or obliterates the evidence.

The paleopathological literature contains a number of reports of skeletal 
neoplasms, and these have been classified into primary benign tumors, conditions which simulate benign tumors, secondary bone involvement by benign neoplasms, malignant primary tumors and primary carcinoma and secondary involvement of bone. Although outwardly extensive, the classification is only represented by specific lesions such as ivory osteoma, osteochondroma, osteoid osteoma, giant cell tumor, osteosarcoma, multiple myeloma, primary and metastic carcinoma and influencing conditions such as intracranial meningiomas, pituitary adenoma and benign pharyngeal tumors. These constitute various claims, and specific examples are still under debate.

Within the orofacial region, the simplest structures found throughout the spectrum of ancient man are the tori of the maxilla, palate and mandible. These show population preferences in some instances and are regarded as variants rather than pathological. Only one dental tumor (a compound composite odontoma) has been found in a cave $e^{[4,14]}$ on the island of Socotra (Indian Ocean) (Fig. 7). Unidentified benign nasopharyngeal tumors have been noted in a number of skulls and these have characteristic restricted bone destruction due to gradual compression, leaving a cavity with rounded or smooth margins. Examples include the affected bones of the nasal area in a Saxon skull, similar changes in the nasal area, orbit and maxilla of a Neolithic skull from Sagsunde (Denmark) and further evidence from the New World. From the Pleistocene period the recovery of the Kanam mandible from East Africa probably provides the earliest example of a malignant tumor in man, which is regarded as an osteosarcoma. However, doubts have now been expressed and some authorities consider the bony reaction to be due to a sub-periosteal ossifying sarcoma. The type of lesion found in skulls which can give rise to a diagnosis of multiple myeloma can equally be applied to metastatic carcinoma, so that a number of skulls covering a wide period of time with osteolytic lesions have accordingly been claimed as one or the other. Skulls falling into this double category of doubt, but with an emphasis mainly toward metastatic carcinoma, have been recovered from the Tepe Hissar site in Iran (3500-3000 B. C.), the Egyptian Old Kingdom III-V Dynasty (2660-2180 B. C.) (Fig. 8), several Neolithic specimens from Europe, Pre-Christian Nubian (400-600 A.D.), the Kérpuszta site of Hungary (10th-11th century A.D.), the European Medieval period and some pre-Columbian examples from the New World ${ }^{[2,4,25,26]}$ (Fig. 9).

Finally, it must be added that evidence of tumors from both literary and artistic sources is sparse and unsatisfactory relative to the field of oral pathology.

\section{Chondrodysplasias}

Chondrodysplasias are a heterogeneous group of bone disorders which are linked with abnormalities of the size and shape of limbs, trunk and skull. Out of this very complicated group, one of the most common forms of dwarfism known as achondroplasia has been identified in ancient man. It is a hereditary condition and becomes manifest in utero, presenting a characteristic appearance at birth of short proximal parts of limbs, a large head with a protruding frontal region, a depressed nasal bridge and a retruded maxilla due to shortness of the base of the skull. Elsewhere, lordosis and dorsolumbar kyphosis are often present. 
Artistic evidence of achondroplastic dwarfs mostly emerges from Egypt, and is represented first by a Predynastic (3200 B. C.) drawing of the "dwarf of Zer" from Abydos, followed by a statuette of the court official Chnoum-Hotep of the Dynasty V (2730-2625 B.C.) from Saqqarah, and also, within the same period, another drawing from the tomb of Deshasheh. A carving (Fig. 10) from near the pyramids of Giza (Dynasty VI, 2460-2270 B. C.) shows Seneb alongside his wife of normal stature, clearly indicating that his dwarfism probably arose from achondroplasia ${ }^{[2,4,25,26]}$. From projected ideas, an amulet of the God Ptah-Seker-Osiris (Dynasty XXVIII, 404-398 B.C.) is represented as an achondroplastic dwarf. Apart from Egypt, achondroplastics have been displayed in a number of forms including Greek vases, a Hellenistic bronze, a relief in India (2nd century A. D.) and Benin (Nigeria) bronzes in the 16th century. The possibility of Turold's groom on the Bayeux tapestry being an achondroplastic must be considered, and similar dwarfs are commonly seen in Renaissance paintings ${ }^{[2,4]}$.

General skeletal evidence of achondroplasia has been found from Predynastic sites including the tomb of King Zer (Dynasty I) and the tomb of King Mersekha. Typical achondroplastic skulls have been recovered, particularly from the temple of Tuthmosis IV (Dynasty XVIII, 1539 B.C.) at Thebes with very characteristic changes to the face and cranial vault. Evidence from Europe has been sparse, while the New World has produced the remains of dwarfs from Florida and Alabama which display some features of achondroplasia ${ }^{[2,4,25,26]}$.

Within the range of malformations of the skeleton, only a few instances of cleft palate have been observed in ancient man. Examples include an early Nubian case, the cleft palate of a child of Anglo-Saxon origin (Fig. 11), a Peruvian skull, two skulls from the prehistoric Newark Site, San Francisco Bay, and several cleft palates of varying degrees in ancient Greenland Eskimos ${ }^{[4,14]}$.

\section{Arthropathies}

The arthropathies are a group of musculoskeletal and connective tissue diseases which commonly affect both man and animals. In medical terms they are a complicated group due to chronicity, variability, biochemical and immunologic complexity, a tendency to exacerbate and remit, and their unknown pathogenesis. From a pathological viewpoint, there are about eight specific states, which can be listed as synovitis, enthesopathy, cartilage degeneration, crystal-induced synovitis, infections of joints, myositis, and focal and general conditions. Arising from these are a number of well known "arthritic" diseases, but in antiquity only those manifested in the bone will be considered. Hence the specific diseases can be shortened to include chronic suppurative arthritis, tuberculous arthritis, rheumatoid arthritis, ankylosing spondylitis, osteoarthritis, osteophytosis and Charcot's arthropathy.

Over the spectrum of ancient man there is evidence that arthritic changes have occurred. Changes have been noted in the general skeleton of Neanderthal Man from Shanidar (Iraq) and another from La Chapelle-aux-Saints (France). Further evidence has also emerged from skeletal remains of Crô-Magnon Man and from populations of the Neolithic, Bronze Age, Viking, Saxon and Medieval periods. In 
addition, bone and joint alterations have been found throughout the Egyptian populations from Pre-Dynastic to Coptic times. Although there is mostly full agreement that these bony changes are arthritic in origin, the problem remains often in the semantics, and a plethora of names have been attached to various states. For example, there have been claims of ankylosing spondylitis which from current knowledge appears more likely to have been osteoarthritis, although definitive cases of ankylosing spondylitis have been found in various cultures including the Egyptian. Osteophytosis or bony 'lipping' is a characteristic of osteoarthritis, but also occurs in rheumatoid arthritis. Knee and hip joints are often affected by brucellosis, typhoid and syphilis, and there are possible examples of hip modification from Tula (Mexico), a Medieval humerus and vertebrae from a Bronze Age skeleton from Jericho thought to have arisen from brucellosis. Charcot's arthropathy, a severe condition usually influencing the limb joints, has been suggested from remains belonging to the Egyptian 1st Dynasty from Abyos. An Egyptian mummy from the Christian period has been reported to show conclusive evidence of uric acid crystals deposited in the joints-a case of gout arthropathy ${ }^{[2,4,25,26]}$.

Relative to oral pathology, apart from the results of trauma, the mandibular joints reflect the specific diseases of rheumatoid arthritis and osteoarthritis. Thus the temporo-mandibular joints of Neanderthal Man from Krapina (Jugoslavia) and La Chapelle-aux-Saints (France) have displayed arthritic changes. From the Skhūl Cave at Mount Carmel (Israel) further mandibles have been recovered showing arthritic deformation of the condyles and reciprocated in the glenoid fossae ${ }^{[23]}$. Only a limited number of mandibular joints with changes to the articular surfaces have been reported throughout the Neolithic, Bronze and Iron Ages (Fig. 12). In the New World arthritic changes of the temporo-mandibular joint have been noted in pre-Columbian California Indians, Virginia, Texas and the Pecos tribes. Peruvian populations have also exhibited varying degrees of osteoarthritis.

\section{Final comments}

In conclusion, this survey of the paleopathological records clearly indicates that the majority of the known organic and microbial disorders manifested in the hard tissues of man and animals are extremely ancient. In addition, there is evidence that the comparative prevalence and severity of various diseases appear to have changed considerably over the course of time. Interpretation of these changes has not been convincing, since the information is based on uncertain diagnoses and records which may be inaccurate, incomplete or damaged in some form. There appears little doubt that ancient man and animals suffered from many diseases, but obviously not all those which now plague the world. The prevalence and severity of disease have undergone some changes, and these are the expression of natural intervention such as hereditary factors concerned in evolutionary adaptation and the influence of socio-economic factors. It is well known in the case of man that each type of civilization has diseases peculiar to it and at each period the various social groups in any community have also differed in this regard. In early man, the size of the interbreeding social units would probably curtail the survival of some 
diseases, and thus the relative isolation of a group would allow a lethal strain of disease to burn itself out within the group. The usefulness of paleopathology and paleoepidemiology must not be obscured by difficulties, since these disciplines not only enable various modern ailments to be traced back to antiquity, both individually and at the population level, but may also provide new insights concerning the manner in which they can manifest themselves.

The prime reason for writing this article was to provide perspective and to stimulate interest in the fascinating problem of oral disease and its general affinities viewed through time; time in this context means the past, the present and the future. Without the first two and some projection of the third, the spectrum of knowledge within oral pathology would remain mostly segmented and unrelated. In simplistic terms it may not be essential to the current practice of oral pathology as a discipline, but it does provide a depth of understanding, a spatial awareness and a satisfaction that the frontiers have been demarcated. The possession of horizons and the prospect of exploring new horizons can be regarded as the cutting edge of the biomedical sword-an integral part of advancing civilization.

\section{References}

[1] Sigerist, H. E.: A History of Medicine 1. Primitive and Archaic Medicine, 38-125, 217-236, 377-425. Oxford University Press, Oxford, 1951

[2] Wells, C.: Bones, Bodies and Disease, 23-160, Thames and Hudson, London, 1964

[3] Chang, K-C.: The Archaeology of Ancient China, 4th edition, 51-53, 60-64, 296-302, 317-339, 361-367, Yale University Press, New Haven, 1986

[4] Brothwell, D. R. and Sandison, A. T. (eds.): Diseases in Antiquity, 20-31, 98-111, 191-246, 249-271, 279-345, 352-389, 423-443, 521-531, 538-595, 599-605, 651-672, Thomas, Springfield, Illinois, 1967

[5] Sigerist, H. E.: A History of Medicine 2. Early Greek, Hindu and Persian Medicine, 11-43, 121-167, 197-207, Oxford University Press, Oxford, 1961

[6] Allchin, B. and Allchin, R.: The Rise of Civilization in India and Pakistan, 97-193, Cambridge University Press, Cambridge, 1982

[7] Zinsser, H.: Rats, Lice and History, 77-93, Little, Brown \& Co., Boston, 1935

[8] Zeuner, F. E.: A History of Domesticated Animals, 123-305, Hutchinson, London, 1963

[9] Ucкo, P. J. and Dimbleby, G. W.: The Domestication and Exploitation of Plants and Animals, 47-172, Duckworth, London, 1969

[10] Mason, I. L.: Evolution of Domestic Animals, 52-99, 106-115, 145-184, Longman, London, 1984

[11] Davis, S. J. M.: The Archaeology of Animals, 61-154, Batsford, London, 1987

[12] Colyer, F.: Variations and Diseases of the Teeth of Animals, 462-738, Bale and Danielsson, London, 1936

[13] Baker, J. and Brothwell, D. R.: Animal Diseases in Archaeology, 33-172, Academic Press, London, 1980

[14] Brothwell, D. R.: Digging up Bones, 3rd Edition, 119-177, British Museum (Natural History), London, 1982

[15] Cornwall, I. W.: Bones for the Archaeologist, 27-33, 74-116, 184-203, Phoenix House, London, 1964

[16] Brothwell, D. R. (ed.): The Skeletal Biology of Earlier Human Populations, 173-203, 205-243, Pergamon Press, Oxford, 1968

[17] Le Gros Clark, W. E.: The Antecedents of Man: An Introduction to the Evolution of Primates, 2nd Ed., 341-356, Edinburgh University Press, Edinburgh, 1962

[18] Napier, J. R. and Napier, P. H.: The Natural History of the Primates, 173-186, British 
Museum (Natural History), London, 1985

[19] Hawkes, J.: History of Mankind: Cultural and Scientific Development, Vol. 1, Part 1, Prehistory, 15-103, 131-185, George Allen and Unwin, London, 1963

[20] Bellwood, P.: Prehistory of the Indo-Malaysian Archipelago, 39-52, 206-231, 246-257, Academic Press, London, 1985

[21] Smith, F. H. and Spencer, F.: The Origins of Modern Humans, 137-209, 252-293, A. R. Liss, New York, 1984

[22] Delson, E. (ed.): Ancestors: The Hard Evidence, 25-85, 104-131, A. R. Liss, New York, 1985

[23] Simmonds, N. W. (ed.): Evolution of Crop Plants, 36-38, 42-44, 91-104, 120-136, 269-273, Longman, London, 1976

[24] Brothwell, D. R. (ed.): Dental Anthropology, 271-288, Pergamon Press, Oxford, 1963

[25] Steinbock, R. T.: Paleopathological Diagnosis and Interpretation: Bone Diseases in Ancient Human Populations, 17-209, 253-411, Thomas, Springfield, Illinois, 1976

[26] Moodie, R. L.: Paleopathology: An Introduction to the Study of Ancient Evidences of Disease, 32-140, 160-178, University of Illinois Press, Urbana, Illinois, 1932 


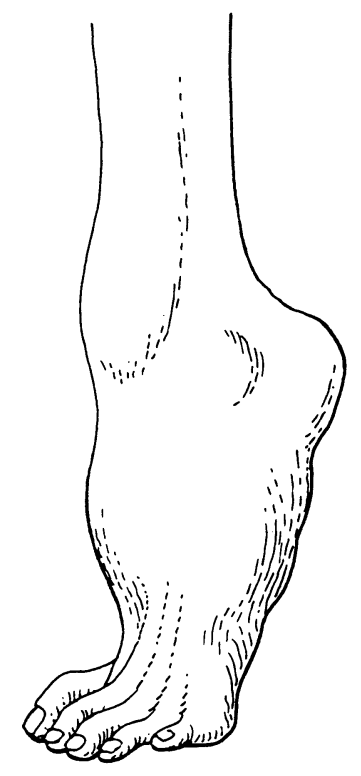

Fig. 1 Left foot of Pharaoh Siptah, XIX Dynasty (1215 B. C.). This is regarded as an example of talipes equinovarus, a form of club-foot which may arise from a congenital deformity or develop during childhood as the result of various pathological conditions. Certainly it is the most common congenital foot deformity, and from Egypt both art and mummy evidence support its existence. In more recent assessments, opinions have also included poliomyelitis, which could result in a similar shape of the foot. Irrespective of the diagnosis, a pathological source is acknowledged.

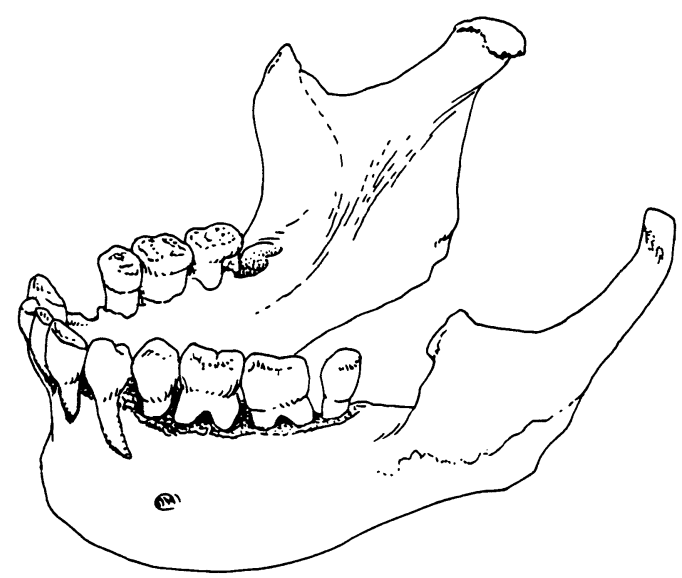

Fig. 2 A mandible recovered from Dolgoi Island, Siberia, which shows evidence of periodontal disease. There is clearly a retreat or recession around the marginal alveolar bone, thus exposing the roots. In addition, the mandible shows microdontia of a single tooth, in this instance, a reduced third molar. 


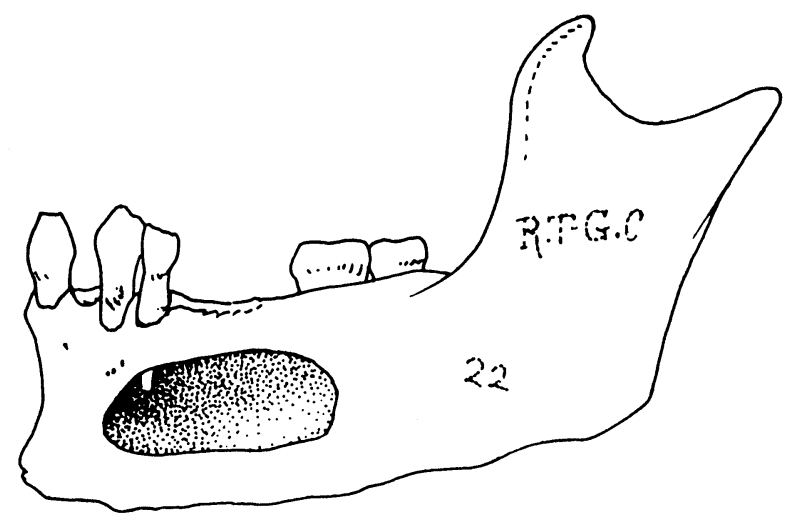

Fig. 3 Mandible from Ras el Tin, Cleopatra's period (50-30 B. C.), showing a cavity on the wall representing either a dental cyst or alveolar abscess (Based on R. L. Moodie, 1923)

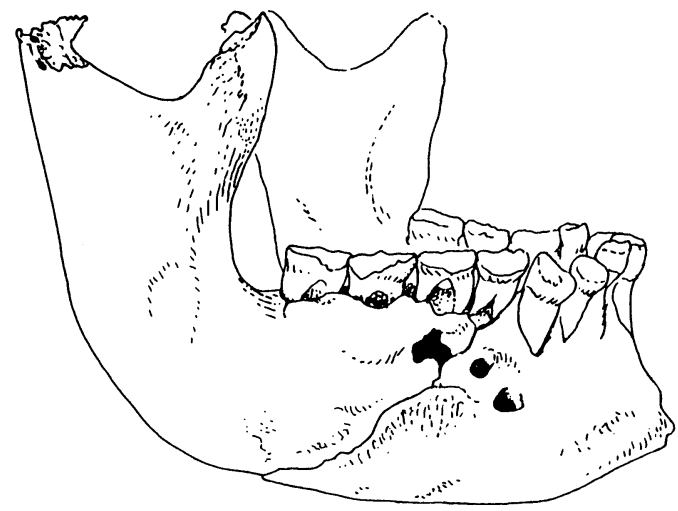

Fig. 4 Mandible from Egypt and dated from the Old Kingdom, IVth Dynasty around 2900 B. C. Found in a tomb excavated by G. A. Reisner at Giza. An interesting example of possible surgical intervention, as demonstrated by two perforations theoretically to drain an alveolar abscess. The teeth show marked attrition, which presumably was followed by necrosis of the pulp tissue of the right first molar. In spite of assertions that bronze instruments were known in the IV Dynasty, reservations still exist, and no drills have been depicted other than a carpenter's painted on the tomb of Rekhmara around 1450 B. C. 


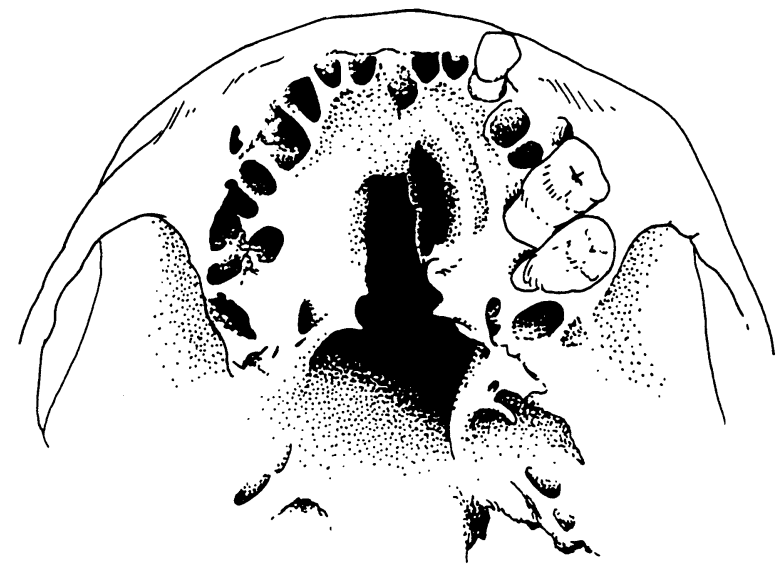

Fig. 5 Considerable destruction of the palatal region of a female Veddah (Sri Lanka) suffering from yaws (treponematoses or specifically Treponema pertenue The nasal region in this specimen has also been attacked (Based on D. R. Brothwell, plate 6.4A, 1981).

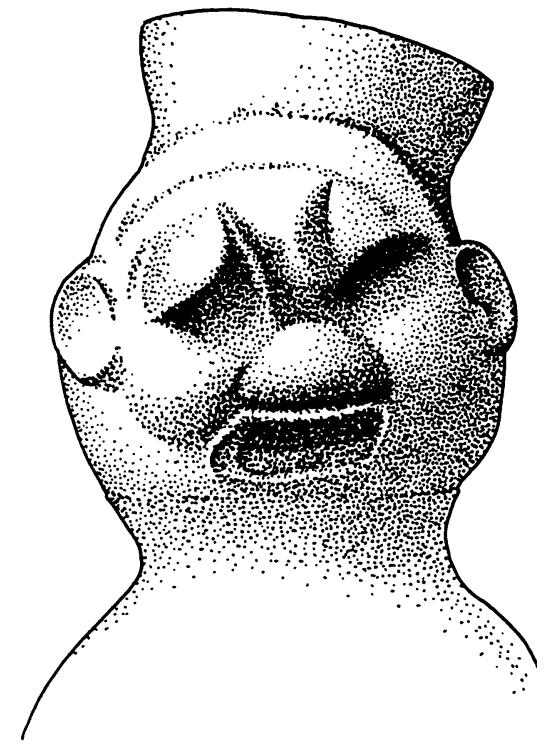

Fig. 6 A sketch of a face on a pottery grain storage jar thought to be Canaanite, from the Amenhotep III temple, Beth-Shan, Jordan (1411-1314 B. C.). The features of the face are practically identical to those found in lepromatous leprosy. The skin of the cheeks is thickened, the forehead has a loose appearance, the eyebrows seem hairless and swollen while folds and creases appear to be heightened. 


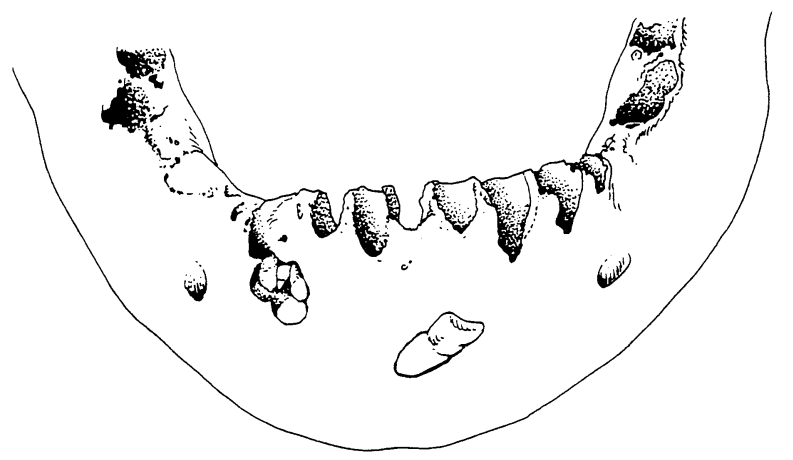

Fig. 7 An example of an odontogenic tumor (compound composite odontoma) found in the mandible of a female originating from the island of Socotra in the Indian Ocean (Based on D. R. Brothwell, plate $6.13 \mathrm{~A}, 1981$ )

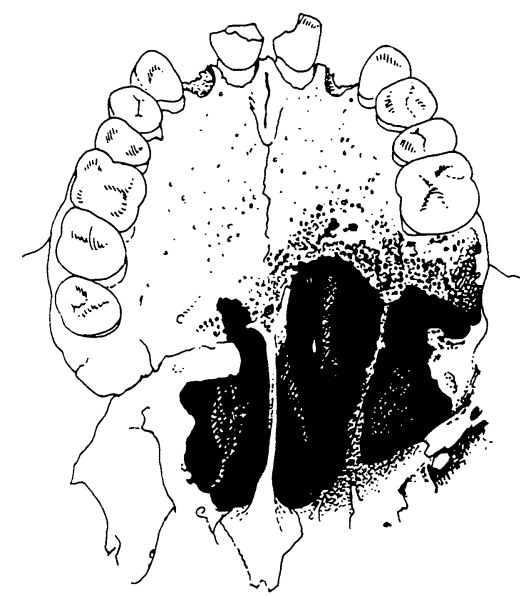

Fig. 8 An adult skull thought to be Egyptian from the III-V Dynasty around $2700 \mathrm{~B}$. C. The posterior area of the left side of the palate, part of the left alveolar ridge and maxillary bone as well as the posterior wall of the antrum, all show erosion due to nasopharyngeal carcinoma (Based on C. Wells, plate 35, 1964). 


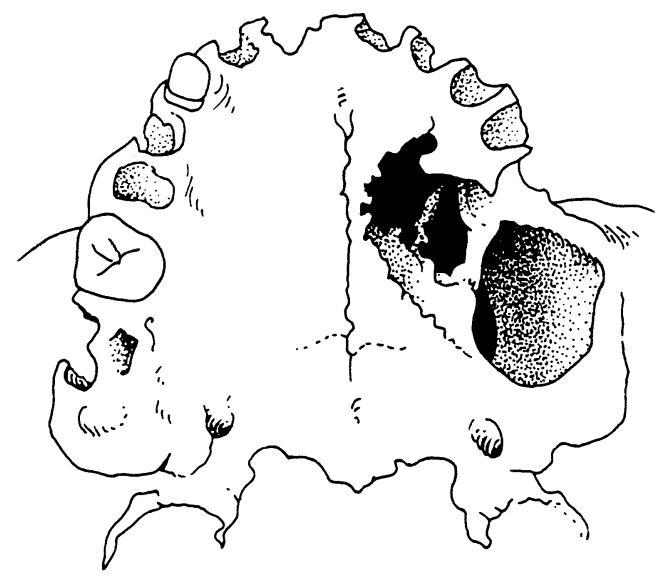

Fig. 9 An early Peruvian skull showing destruction of the left maxillo-alveolar region caused by an unknown tumor of either a benign invasive type or a carcinomatous type (Based on R. L. Moodie, 1926)

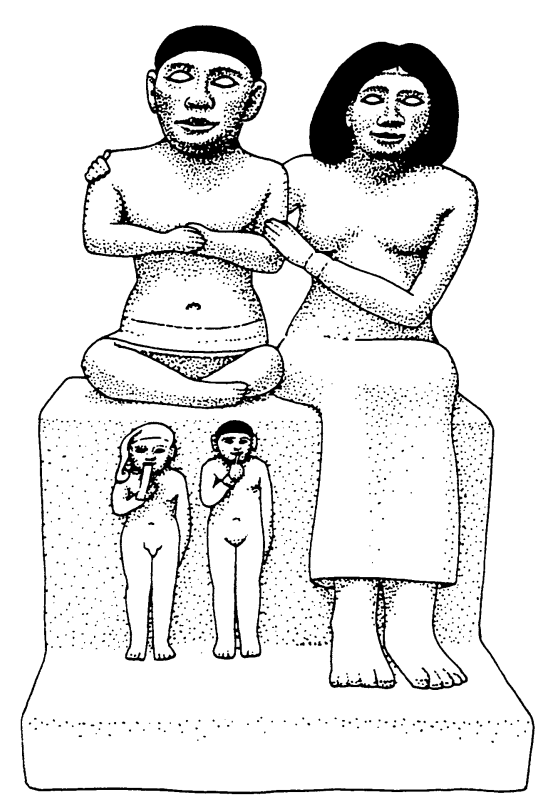

Fig. 10 A sketch of a painted limestone carving located near the pyramids of Giza, probably Dynasty VI (2460-2270 B. C.) The carving depicts the dwarf Seneb, contrasted physically with his normal-sized wife and children. Current opinion favors that Seneb suffered from achondroplasia (Displayed in Cairo and discovered by the expedition of the Vienna Academy of Science, 1927). 


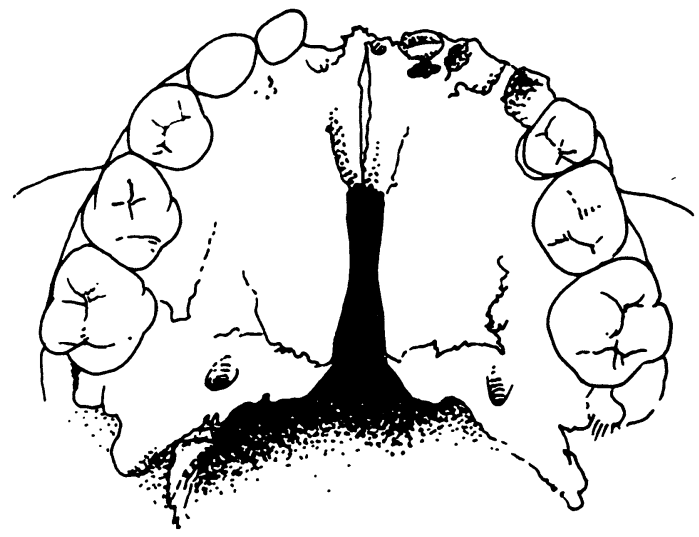

Fig. 11 A cleft palate of a child of Anglo-Saxon origin. Although there are a number of skeletal malformations, only a small number of cleft palates have been recorded. Clefts can occur in the palate and in the alveolar process of the maxilla, and vary considerably in extent. The lack of instances from earlier populations may well be linked to the high mortality rate of infants with cleft deformities, and the visible defects may have prejudiced child-care in primitive or pre-literate communities.

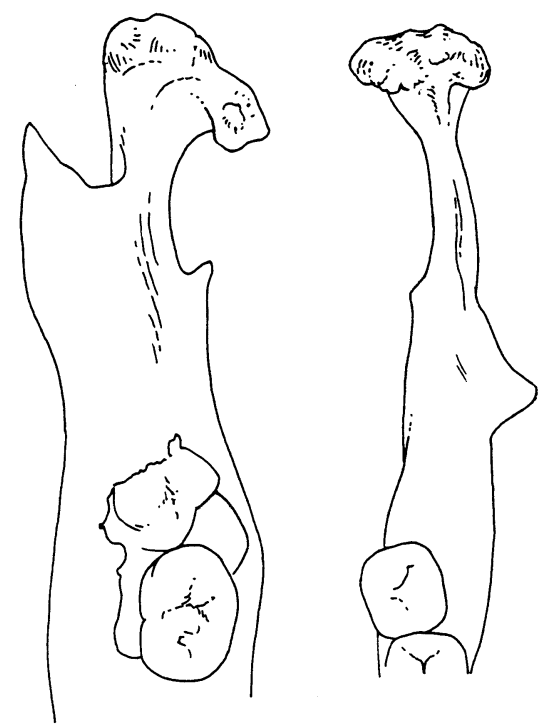

Fig. 12 An example of osteo-arthritic changes in mandibular condyles based on Nubian material from around 1580-1090 B. C. and the Danish Iron Age. The disease is linked with aging and appears to be dependent on wear and tear of the temporomandibular joint. Among the changes seen are porous and rough articular surfaces (as shown above), osteophytic lipping where the joint capsule is attached to the bone, and wear and tear stimulate exostoses from the periosteum. Considerable amounts of bone can be formed, even to the extent of filling up the glenoid fossa. 